\title{
Rapid Recovery of Hypothalamic-Pituitary Axis after Successful Resection of an ACTH-secreting Neuroendocrine Tumor
}

\author{
Yuichi Takashi, Yuka Kinoshita, Noriko Makita, Manabu Taguchi, Katsutoshi Takahashi, \\ Masaomi Nangaku and Seiji Fukumoto
}

\begin{abstract}
We describe a 30-year-old man with ectopic adrenocorticotropic hormone (ACTH) syndrome. Before the operation, there was no diurnal variation of $\mathrm{ACTH}$, and $\mathrm{ACTH}$ did not respond to $\mathrm{CRH}$ or dexamethasone suppression tests. These abnormalities disappeared after the removal of a neuroendocrine tumor in the lung. In addition, plasma ACTH was measureable at as early as postoperative day 3 with ACTH levels increasing thereafter. Furthermore, an insulin tolerance test and inferior petrosal sinus sampling indicated that ACTH was secreted from the pituitary. This case indicates that the hypothalamic-pituitary function can recover within a couple of weeks after curative surgery for ectopic ACTH syndrome.
\end{abstract}

Key words: hypothalamic-pituitary-adrenal axis, ectopic ACTH syndrome, Cushing's syndrome, neuroendocrine tumor

(Intern Med 54: 2201-2205, 2015)

(DOI: 10.2169/internalmedicine.54.4915)

\section{Introduction}

Ectopic adrenocorticotropic hormone (ACTH) syndrome has been a challenging disease for clinicians $(1,2)$. First, it is sometimes difficult to biochemically differentiate ectopic ACTH syndrome from Cushing's disease (3). Second, it may not be easy to find the responsible tumors for ectopic ACTH syndrome (4). Third, the causative tumors cannot be completely removed in some patients and other therapies need to be considered to control Cushing's syndrome (5). Fourth, the curative surgery for ectopic ACTH syndrome causes secondary adrenal insufficiency due to the suppression of the hypothalamic-pituitary axis by preoperative high cortisol (6). Finally, when ACTH and cortisol levels increase after surgery, it is necessary to differentiate the recovery of hypothalamic-pituitary function from recurrence or residual tumors secreting ACTH.

It is generally believed that it takes from months to more than a year for full recovery of the hypothalamic-pituitaryadrenal axis after curative surgery for Cushing's syn- drome (7). During this period, glucocorticoid replacement therapy is maintained (8). Early postoperative recovery of ACTH and cortisol secretion therefore suggests the presence of residual tumors for ACTH-dependent Cushing's syndrome (9-13). Avgerinos et al. reported that a normal CRH test response was observed in 3 patients at 1-2 weeks after the surgery who later developed recurrent Cushing's disease (6). However, the same authors also reported that the response to CRH was normal in 3 other cured patients at 12 weeks after surgery for Cushing's disease (6). Therefore, it is possible that the degree of the suppression of the hypothalamic-pituitary function by glucocorticoid excess is quite variable among patients with Cushing's disease. However, there are only limited data on the time course of the recovery of hypothalamic-pituitary-adrenal axis in patients with ectopic ACTH syndrome.

We herein report the case of a patient with ectopic ACTH syndrome caused by bronchial neuroendocrine tumor whose ACTH and cortisol levels recovered within 10 days after curative surgery. Careful endocrine examinations indicated that the patient's ACTH was secreted from the pituitary and 


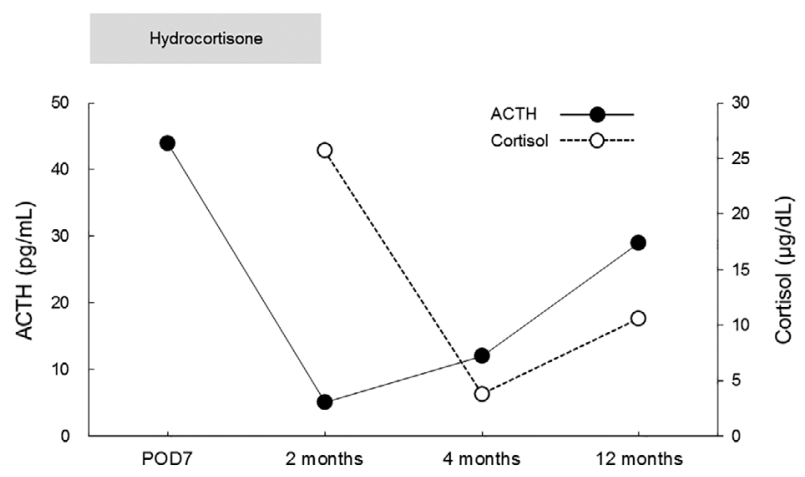

Figure 1. Clinical course after the first surgery of the patient at another hospital. Plasma ACTH was increased at as early as postoperative day 7 and 2 months after the replacement of hydrocortisone was terminated. The patient showed no sign of recurrence of ectopic ACTH syndrome for 9 years after surgery.

that there was no evidence of the residual tumor. This case indicates that hypothalamic-pituitary function can recover within a couple of weeks after curative surgery for ectopic ACTH syndrome. This information may be important for preventing unnecessary and excess glucocorticoid administration after surgery for ectopic ACTH syndrome.

\section{Case Report}

A 30-year-old man was admitted to our hospital complaining of skin pigmentation and general malaise. He had had a history of ectopic ACTH syndrome caused by a right bronchial neuroendocrine tumor 9 years before this admission. At that time, he complained of general malaise and noticed pigmentation in his hands and abdomen. His serum cortisol level was more than $80 \mu \mathrm{g} / \mathrm{dL}(2,200 \mathrm{nmol} / \mathrm{L})$ and plasma ACTH was $827 \mathrm{pg} / \mathrm{mL}$ (181.9 pmol/L). A subsequent evaluation at another hospital revealed a bronchial tumor and he was diagnosed with ectopic ACTH syndrome. He then underwent partial lobectomy of his right lung and a neuroendocrine tumor was pathologically diagnosed. Immunohistochemical staining for ACTH was positive. After the operation, his symptoms clearly improved and serum cortisol and plasma ACTH levels normalized. The postoperative course of the patient at another hospital is shown in Fig. 1. Plasma ACTH was $44 \mathrm{pg} / \mathrm{mL}(9.7 \mathrm{pmol} / \mathrm{L})$ at as early as postoperative day 7. Two months later, hydrocortisone replacement was terminated. Thereafter, he showed no sign of recurrence of ectopic ACTH syndrome and the follow-up in that hospital was terminated 4 years prior to this presentation.

The patient again began to recognize pigmentation in the creases of the proximal interphalangeal joints 1 year ago. A medical checkup performed two months prior to admission indicated hypertension and hyperglycemia. His blood pressure was 169/96 mmHg and fasting plasma glucose was 177 $\mathrm{mg} / \mathrm{dL}(9.82 \mathrm{mmol} / \mathrm{L})$. Finally, one month prior to admis-
Table 1. Endocrinological Examinations before the Operation.

\begin{tabular}{|c|c|c|c|c|c|}
\hline \multicolumn{6}{|l|}{ Diurnal variation } \\
\hline & \multicolumn{2}{|c|}{$0800 \mathrm{~h}$} & \multicolumn{3}{|c|}{$2300 \mathrm{~h}$} \\
\hline ACTH (pg/mL) & \multicolumn{2}{|c|}{258.9} & \multicolumn{3}{|c|}{305.8} \\
\hline Cortisol $(\mu \mathrm{g} / \mathrm{dL})$ & \multicolumn{2}{|c|}{75.3} & \multicolumn{3}{|c|}{74.5} \\
\hline \multicolumn{3}{|c|}{$0.5 \mathrm{mg}$ dexamethasone suppression test } & \multicolumn{3}{|c|}{$8 \mathrm{mg}$ dexamethasone suppression test } \\
\hline $\mathrm{ACTH}(\mathrm{pg} / \mathrm{mL})$ & \multicolumn{2}{|l|}{407.8} & $\mathrm{pg} / \mathrm{ml})$ & \multicolumn{2}{|c|}{282.6} \\
\hline Cortisol $(\mu \mathrm{g} / \mathrm{dL})$ & \multicolumn{2}{|l|}{76.2} & $(\mu \mathrm{g} / \mathrm{dl})$ & \multicolumn{2}{|c|}{70.6} \\
\hline \multicolumn{6}{|l|}{ CRH test } \\
\hline & $0 \mathrm{~min}$ & $30 \mathrm{~min}$ & $60 \mathrm{~min}$ & $90 \mathrm{~min}$ & $120 \mathrm{~min}$ \\
\hline ACTH $(\mathrm{pg} / \mathrm{mL})$ & 244.0 & 225.4 & 246.6 & 241.2 & 235.4 \\
\hline Cortisol $(\mu \mathrm{g} / \mathrm{dL})$ & 69.7 & 68.8 & 66.3 & 67.3 & 70.8 \\
\hline
\end{tabular}

sion, he began to feel general malaise and thereafter visited our hospital for the first time. Cushing's syndrome was suspected because of hypertension $(194 / 110 \mathrm{mmHg})$, hyperglycemia $[161 \mathrm{mg} / \mathrm{dL}(8.94 \mathrm{mmol} / \mathrm{L})]$, neutrophilia, eosinopenia, lymphopenia (white blood cells $8,200 / \mu \mathrm{L}$, neutrophil $92.1 \%$, eosinophil $0.0 \%$, lymphocyte $3.1 \%$ ) and hypokalemia $(2.7$ $\mathrm{mEq} / \mathrm{L})$. His serum cortisol was $74.5 \mu \mathrm{g} / \mathrm{dL}(2,056 \mathrm{nmol} / \mathrm{L})$ and plasma ACTH was $268.9 \mathrm{pg} / \mathrm{mL}$ (59.2 pmol/L). Serum cortisol and plasma ACTH were measured by an electrochemiluminescence immunoassay (ECLusys, Roche Diagnostics Japan, Tokyo, Japan). The cross reactivity with big ACTHs such as proopiomelanocortin (POMC) and pro$\mathrm{ACTH}$ in this assay was approximately $1.5 \%$, indicating that the high ACTH in this patient was biologically active. From his past history, the recurrence of ectopic ACTH syndrome was considered and he was admitted to our hospital.

His height was $181.0 \mathrm{~cm}$ and body weight was $74.3 \mathrm{~kg}$. He had a moon face, facial acne and bilateral leg edema. Increased pigmentation was observed on his face, the creases of proximal interphalangeal joints, elbows, chest and abdomen. He also showed proximal muscle weakness. The results of endocrinological examinations are shown in Table 1. Plasma ACTH and serum cortisol were clearly elevated with no diurnal variation. High cortisol levels were not suppressed by either $0.5 \mathrm{mg}$ or $8 \mathrm{mg}$ dexamethasone suppression tests. The plasma ACTH and serum cortisol levels did not differ on $\mathrm{CRH}$ test. The urinary free cortisol level, which reached 15,650 $\mu \mathrm{g} / 24 \mathrm{~h}(43,194 \mathrm{nmol} / \mathrm{day})$, was remarkably high. In addition, plasma aldosterone concentrations and DHEA-S levels were $14.5 \mathrm{ng} / \mathrm{dL}(0.4 \mathrm{nmol} / \mathrm{L})$ and $315 \mu \mathrm{g} / \mathrm{dL}(8.5 \mu \mathrm{mol} / \mathrm{L})$. All of these data indicated that he was suffering from ACTH-dependent Cushing's syndrome and that ectopic ACTH syndrome was the most likely diagnosis.

Contrast enhanced computed tomography (CT) revealed lymphadenopathy along the bronchus in the right inferior lobe, and a recurrence of the neuroendocrine tumor was suspected. CT also revealed a remarkable swelling of both adrenal glands. Positron emission tomography (PET)/CT indicated the uptake of fluorodeoxyglucose in that lymph node, with a maximum standardized uptake value (SUV) of 2.2. Pituitary magnetic resonance imaging (MRI) showed no sign 


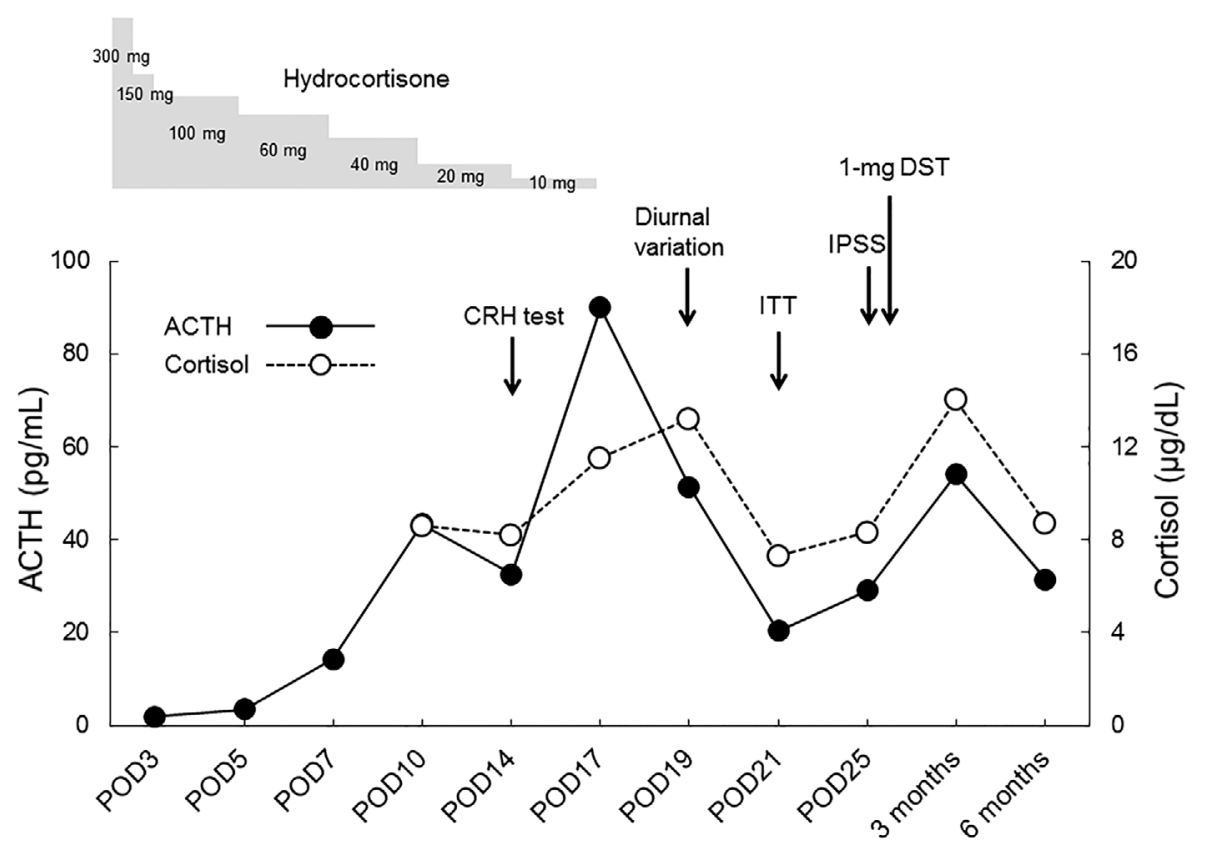

Figure 2. Clinical course after the second surgery of the patient. After the patient's cortisol levels were controlled, he underwent resection of the inferior and middle lobes of his right lung with lymph node dissection. Hydrocortisone was administered during the perioperative period and gradually tapered. POD: postoperative day, ITT: insulin tolerance test, IPSS: inferior petrosal sinus sampling, DST: dexamethasone suppression test.

of pituitary adenoma.

From these results, he was diagnosed with ectopic ACTH syndrome caused by lymph node metastasis of a neuroendocrine tumor.

Prior to the operation, it was necessary to control of his cortisol levels. First, we attempted to control his cortisol levels by decreasing ACTH levels. Thus, $300 \mu \mathrm{g} /$ day of octoreotide was administered by injection. Subsequently, his ACTH and cortisol levels decreased to $203.2 \mathrm{pg} / \mathrm{mL}$ (44.7 $\mathrm{pmol} / \mathrm{L})$ and $43.3 \mu \mathrm{g} / \mathrm{dL}(1,195 \mathrm{nmol} / \mathrm{L})$ respectively. We thought these values were too high for the operation and 1 g/day of metyrapone was added. After controlling his ACTH and cortisol levels to about $92.7 \mathrm{pg} / \mathrm{mL}(20.4 \mathrm{pmol} / \mathrm{L})$ and $25 \mu \mathrm{g} / \mathrm{dL}$ (690 nmol/L), respectively, with the combination of octreotide injections and metyrapone, he underwent resection of the inferior and middle lobes of his right lung with lymph node dissection. Immunohistochemical staining indicated that the tumor cells were positive for ACTH, synaptophysin, chromogranin and CD56. Ten percent of cells were Ki-67-positive and a grade 2 neuroendocrine tumor was pathologically diagnosed (14).

The postoperative clinical course of the patient is shown in Fig. 2. Hydrocortisone was administered during the perioperative period and gradually tapered. Unexpectedly, plasma ACTH was measurable at $1.88 \mathrm{pg} / \mathrm{mL}(0.41 \mathrm{pmol} / \mathrm{L})$ from as early as postoperative day 3. In addition, ACTH increased thereafter while hydrocortisone was administered. In contrast, the morning serum cortisol level was $8.6 \mu \mathrm{g} / \mathrm{dL}$ (237.4 nmol/L) at postoperative day 10 , when he received $40 \mathrm{mg}$ hydrocortisone $(20 \mathrm{mg}$ after breakfast, $10 \mathrm{mg}$ after lunch and $10 \mathrm{mg}$ after dinner). Because the half-life of the administered hydrocortisone is about 2 hours, the level of serum hydrocortisone after 12 hours would be less than 5 $\mu \mathrm{g} / \mathrm{dL}(138 \mathrm{nmol} / \mathrm{L})$, even if the drug is postulated to distribute only to the intravascular fluid. Therefore, his morning serum cortisol level of $8.6 \mu \mathrm{g} / \mathrm{dL}$ (237.4 nmol/L) was considered, at least in part, to reflect endogenous cortisol secretion. Hydrocortisone replacement was therefore rather rapidly tapered thereafter until it was terminated at postoperative day 17. The rapid recovery of ACTH and cortisol levels suggested that the remaining tumoral tissues were producing ACTH. However, all of the suspected lesions were operatively resected and the preoperative studies did not reveal any tumorous tissues other than the resected lymph node. We therefore tried to determine the source of ACTH by endocrinological examinations. Diurnal variation of ACTH and cortisol was evaluated at postoperative day 19 without hydrocortisone replacement. In contrast to the preoperative values, clear diurnal variation of both ACTH and cortisol was observed (Table 2). In addition, $1 \mathrm{mg}$ dexamethasone suppressed ACTH and cortisol levels, and both $\mathrm{ACTH}$ and cortisol responded to $\mathrm{CRH}$ (Table 2). Furthermore, we conducted an insulin tolerance test (ITT). As shown in Table 2, hypoglycemia efficiently enhanced ACTH levels, which was followed by an increase of cortisol, indicating that the secretion of ACTH was controlled by the hypothalamus (15). All of these results suggested that ACTH was secreted from the pituitary. To confirm that the pituitary was the source of ACTH in this patient, inferior petrosal sinus sampling (IPSS) and a CRH test were conducted after 
Table 2. Endocrinological Examinations after the Operation.

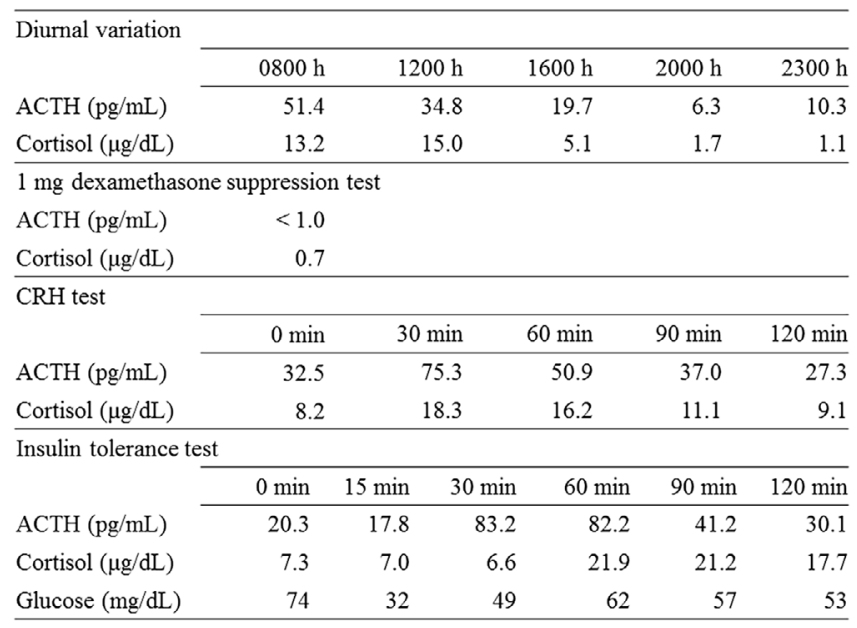

written informed consent was obtained. The patient also expressed that it was his will to determine the source of ACTH. However, there was no clear difference in the PRL levels between right IPS and peripheral blood suggesting unsuccessful IPS catheterization (16). Nevertheless, as shown in Table 3, the ACTH/prolactin (PRL) ratio was higher in the right IPS than in peripheral blood (left median cubital vein) at 10 minutes after $\mathrm{CRH}$ administration (16-18). These results indicated that the pituitary was secreting ACTH and that it was responsive to CRH. We also performed an RT-PCR analysis of the resected tumor because we considered the possibility of an ectopic CRH producing tumor. While the expression of POMC was confirmed, the expression of $C R H$ was not detected in the lymph node metastasis of the neuroendocrine tumor. At the time of discharge from our hospital, the patient's blood pressure was $122 / 64 \mathrm{mmHg}$, fasting plasma glucose was 74 $\mathrm{mg} / \mathrm{dL}(4.1 \mathrm{mmol} / \mathrm{L})$ and serum potassium was $3.9 \mathrm{mEq} / \mathrm{L}$. In addition, plasma aldosterone concentrations were $14.1 \mathrm{ng} /$ $\mathrm{dL}(0.4 \mathrm{nmol} / \mathrm{L})$ and DHEA-S levels were $90 \mu \mathrm{g} / \mathrm{dL}(2.4$ $\mu \mathrm{mol} / \mathrm{L})$. At 6 months after surgery, he showed no sign of Cushing's syndrome or recurrence of the tumor.

\section{Discussion}

We herein describe a patient with ectopic ACTH syndrome caused by a metastatic neuroendocrine tumor in whom ACTH secretion from the pituitary recovered within 10 days after the successful surgical removal of the responsible tumor. After achieving a surgical cure of Cushing's syndrome, it is believed that suppression of the hypothalamic-pituitary-adrenal axis causes secondary adrenal insufficiency that lasts for about 1 year (6). Doherty et al. reported that a median time of 19 months was necessary for the discontinuation of glucocorticoid replacement in surgically treated patients with Cushing's syndrome by adrenal adenomas (19). This result suggests that in some patients the inhibition of hypothalamic-pituitary-adrenal axis may last
Table 3. Inferior Petrosal Sinus Sampling with CRH Test.

\begin{tabular}{llrrrr}
\hline & & 0 min & 3 min & 5 min & 10 min \\
\hline Rt. IPS & ACTH $(\mathrm{pg} / \mathrm{mL})$ & 29.8 & 32.9 & 44.6 & 74.4 \\
& PRL $(\mathrm{ng} / \mathrm{mL})$ & 18 & 22 & 27 & 31 \\
& ACTH/PRL & 1.7 & 1.5 & 1.7 & 2.4 \\
\multirow{5}{*}{ Peripheral } & ACTH (pg/mL) & 20.5 & 36.7 & 25.5 & 40.8 \\
& PRL (ng/mL) & 19 & 20 & 25 & 28 \\
& ACTH/PRL & 1.1 & 1.8 & 1.0 & 1.5 \\
\hline
\end{tabular}

for more than one year after curable surgery for Cushing's syndrome. Glucocorticoid replacement therapy is thus maintained for several months to a year and sometimes even longer after resection of the responsible tumors for Cushing's syndrome including ectopic ACTH syndrome $(8,20)$.

Avgerinos et al. showed that the response to CRH is suppressed at 1 to 2 weeks after the surgery in most patients with Cushing's syndrome, including 2 patients with ectopic ACTH syndrome (6). However, they also found a normal response to CRH in 3 cured patients with Cushing's disease (6). Similarly, Cunha et al. reported that baseline and CRH-stimulated ACTH levels recovered at 48 hours after discontinuation of dexamethasone therapy for 28 days in children with acute lymphoid leukemia (21). While the subjects in these two studies are quite different, it is still possible (at least in some patients) that the hypothalamicpituitary-adrenal axis recovers soon after the release of glucocorticoid excess.

Theoretically, the early increase of ACTH after surgery in patients with ectopic ACTH syndrome suggests the residual tumoral tissue secreting ACTH. This was a serious concern in our patient. Therefore, we carefully analyzed the source of ACTH in this patient. Before the operation, there was no diurnal variation of $\mathrm{ACTH}$, and $\mathrm{ACTH}$ did not respond to CRH or dexamethasone suppression tests. In contrast, all of these abnormalities disappeared after the surgery. In addition, ITT and IPSS indicated that ACTH was secreted from his pituitary. Furthermore, there was no evidence of recurrence of the tumor or the relapse of Cushing's syndrome at 6 months after the surgery. Because Cushing's syndrome in this patient relapsed 9 years after the initial surgery, longer observation is clearly necessary. However, all of these results indicated that the hypothalamic-pituitary axis of this patient recovered within a couple of weeks after the second surgery. The hypothalamic-pituitary axis of this patient also recovered within 2 months after the first surgery which had been performed 9 year previously. The similar clinical courses in the two postoperative periods indicate that the suppression of hypothalamic-pituitary function by glucocorticoids is not severe in this patient. The mechanisms that determine the degree and duration of the suppression of the hypothalamic-pituitary-adrenal axis after the curative surgery for Cushing's syndrome are currently unknown. Therefore, in order to prevent unnecessary and excess glucocorticoid replacement it may be prudent to carefully monitor the hypothalamic-pituitary-adrenal function in surgically treated 
patients with ectopic ACTH syndrome.

The authors state that they have no Conflict of Interest (COI).

\section{References}

1. Newell-Price J, Bertagna X, Grossman AB, Nieman LK. Cushing's syndrome. Lancet 367: 1605-1617, 2006.

2. Alexandraki KI, Grossman AB. The ectopic ACTH syndrome. Rev Endocr Metab Disord 11: 117-126, 2010.

3. Invitti C, Pecori Giraldi F, de Martin M, Cavagnini F. Diagnosis and management of Cushing's syndrome: results of an Italian multicentre study. Study Group of the Italian Society of Endocrinology on the Pathophysiology of the Hypothalamic-PituitaryAdrenal Axis. J Clin Endocrinol Metab 84: 440-448, 1999.

4. Sahdev A, Reznek RH, Evanson J, Grossman AB. Imaging in Cushing's syndrome. Arq Bras Endocrinol Metabol 51: 13191328, 2007.

5. Biller BM, Grossman AB, Stewart PM, et al. Treatment of adrenocorticotropin-dependent Cushing's syndrome: a consensus statement. J Clin Endocrinol Metab 93: 2454-2462, 2008.

6. Avgerinos PC, Chrousos GP, Nieman LK, Oldfield EH, Loriaux DL, Cutler GB Jr. The corticotropin-releasing hormone test in the postoperative evaluation of patients with Cushing's syndrome. J Clin Endocrinol Metab 65: 906-913, 1987.

7. Graber AL, Ney RL, Nicholson WE, Island DP, Liddle GW. Natural history of pituitary-adrenal recovery following long-term suppression with corticosteroids. J Clin Endocrinol Metab 25: 11-16, 1965.

8. Shen WT, Lee J, Kebebew E, Clark OH, Duh QY. Selective use of steroid replacement after adrenalectomy: lessons from 331 consecutive cases. Arch Surg 141: 771-774; discussion 774-776, 2006.

9. Trainer PJ, Lawrie HS, Verhelst J, et al. Transsphenoidal resection in Cushing's disease: undetectable serum cortisol as the definition of successful treatment. Clin Endocrinol (Oxf) 38: 73-78, 1993.

10. McCance DR, Besser M, Atkinson AB. Assessment of cure after transsphenoidal surgery for Cushing's disease. Clin Endocrinol (Oxf) 44: 1-6, 1996.

11. Imaki $T$, Tsushima $T$, Hizuka $N$, et al. Postoperative plasma corti- sol levels predict long-term outcome in patients with Cushing's disease and determine which patients should be treated with pituitary irradiation after surgery. Endocr J 48: 53-62, 2001.

12. Yap LB, Turner HE, Adams CB, Wass JA. Undetectable postoperative cortisol does not always predict long-term remission in Cushing's disease: a single centre audit. Clin Endocrinol (Oxf) 56: 25-31, 2002.

13. Lindsay JR, Oldfield EH, Stratakis CA, Nieman LK. The postoperative basal cortisol and CRH tests for prediction of long-term remission from Cushing's disease after transsphenoidal surgery. J Clin Endocrinol Metab 96: 2057-2064, 2011.

14. Rindi G, Petrone G, Inzani F. The 2010 WHO classification of digestive neuroendocrine neoplasms: a critical appraisal four years after its introduction. Endocr Pathol 25: 186-192, 2014.

15. Fitzgerald PA, Aron DC, Findling JW, et al. Cushing's disease: transient secondary adrenal insufficiency after selective removal of pituitary microadenomas; evidence for a pituitary origin. J Clin Endocrinol Metab 54: 413-422, 1982.

16. Findling JW, Kehoe ME, Raff $H$. Identification of patients with Cushing's disease with negative pituitary adrenocorticotropin gradients during inferior petrosal sinus sampling: prolactin as an index of pituitary venous effluent. J Clin Endocrinol Metab 89: 6005-6009, 2004.

17. Oldfield EH, Doppman JL, Nieman LK, et al. Petrosal sinus sampling with and without corticotropin-releasing hormone for the differential diagnosis of Cushing's syndrome. N Engl J Med 325: 897-905, 1991.

18. Lad SP, Patil CG, Laws ER Jr, Katznelson L. The role of inferior petrosal sinus sampling in the diagnostic localization of Cushing's disease. Neurosurg Focus 23: E2, 2007.

19. Doherty GM, Nieman LK, Cutler GB Jr, Chrousos GP, Norton JA. Time to recovery of the hypothalamic-pituitary-adrenal axis after curative resection of adrenal tumors in patients with Cushing's syndrome. Surgery 108: 1085-1090, 1990.

20. White A, Ray DW, Talbot A, Abraham P, Thody AJ, Bevan JS. Cushing's syndrome due to phaeochromocytoma secreting the precursors of adrenocorticotropin. J Clin Endocrinol Metab 85: 47714775, 2000.

21. Cunha Cde F, Silva IN, Finch FL. Early adrenocortical recovery after glucocorticoid therapy in children with leukemia. J Clin Endocrinol Metab 89: 2797-2802, 2004.

(C) 2015 The Japanese Society of Internal Medicine http://www.naika.or.jp/imonline/index.html 